\title{
A segurança democrática e o poder no sistema mundial
}

\section{Democratic security and power in the world-system}

\begin{abstract}
Ana Maria Schenegoski
Edu Silvestre de Albuquerque

Universidade Estadual de Ponta Grossa

Resumo: O presente artigo tem por objetivo analisar a relação entre segurança democrática e poder no sistema mundial e nos processos de integração regional tendo como referencial teórico Khanna. Iniciamos pelo conceito de democracia e sua evolução segundo o contexto histórico-geográfico analisado. Em seguida, verificamos a eficácia do modelo democrático nas relações internacionais. São analisados os casos sul-americano, europeu e asiático numa perspectiva interestatal e são destacados os processos de integração regional em curso. Observa-se um gap entre a democracia interna aos Estados nacionais e a democracia na relação entre os atores estatais, inclusive no interior dos processos integracionistas regionais.
\end{abstract}

Palavras-Chaves: Democracia. Poder. Sistema-Mundo.

\begin{abstract}
This article aims at examining the relationship between democratic security and power in the world-system and in the regional integration processes, based on the theoretical works of Khanna (2008). In order to do so, it starts with an analysis of the concept of democracy and its evolution according to the geographical and historical context in question. Afterwards, it seeks to verify the effectiveness of the democratic model in international relations. The South-American, European and Asian cases are subsequently analyzed in an inter-State perspective, highlighting the underway regional integration processes. There is a gap between the national States internal democracy and the democracy observed in the relationship between actors, as well as within regional integrationist processes.
\end{abstract}

Keywords: Democracy. Power. World-system. 


\section{INTRODUÇÃO}

A democracia e o livre-mercado formam os "mantras" do mundo pós-Guerra Fria. Os novos paradigmas para países e regiões recém-saídos de regimes totalitários são de construção de Estados democráticos, de sociedades democráticas, mas o que isso implica quando o conceito de democracia é transladado ao plano internacional? Como se estabelece a ordem democrática nas relações interestatais?

No sentido liberal, a democracia é uma forma de governo baseada nas liberdades civis da população, entendendo como liberdades civis o direito a eleições livres, a liberdade de expressão, a liberdade para professar uma fé e o respeito aos direitos individuais. Este último é um dos pontos centrais que debatemos neste artigo, pois num viés cultural do conceito de democracia liberal, o individualismo representa, sobretudo, um valor ocidental (HUNTINGTON, 1997). Já na visão marxista, o individualismo expressa fundamentalmente os interesses liberais ou burgueses de livre mercado e de propriedade privada.

Com efeito, o Estado moderno é uma democracia indireta, forma representativa por excelência, em que a vontade geral é consubstanciada numa parcela da população eleita pela maioria. A liberdade política para a maioria dos cidadãos é, portanto, fundamentalmente, de votar e ser votado.

Essa dissociação crescente entre sociedade política e sociedade civil é um dos sintomas mais graves da crise de legitimidade da maioria dos governos na atualidade (GANDIN, 1998). A adoção de formas de democracia direta se mostra cada vez mais limitada nas sociedades modernas, onde os temas tornam-se mais complexos e o tempo mais acelerado (SANTOS, 1997), e isto é verdadeiro mesmo para as democracias ocidentais mais antigas.
A origem da democracia liberal ou moderna remonta à Era das Revoluções, segundo Hobsbawm, foi no período de 1789 a 1848 (HOBSBAWN, 1996), mas a revolução também já estava presente na bandeira federalista na Guerra de Independência dos Estados Unidos (1776), mas ocorre principalmente nos princípios de liberdade, igualdade e fraternidade da Revolução Francesa (1789) e na Revolução Industrial Contemporânea. Onde a burguesia subiu ao poder, destruía os resquícios do domínio Aristocrático e do Absolutismo para instaurar a democracia de massas e um Estado Laico. Assim, instituiu as noções de cidadania e de representação política.

Mas a democracia liberal afirmada pela burguesia trouxe também o direito de propriedade privada e de livre-mercado, representando a ampliação das assimetrias no campo internacional. Como fez notar Edward Carr (1981) acerca do sistema internacional pós-Guerra Fria, o universalismo afirmado pelo liberalismo não é diferente da democracia, ambos mais formais e retóricos que efetivamente distribuidores de poder. Joseph Nye (2005), afirma que a era informacional atual não fez mais que ampliar as assimetrias de poder nas relações internacionais.

Visando aprofundar essa discussão esboçada, este artigo questiona os limites dos principais conceitos de democracia em voga quando confrontados com contextos histórico-geográficos determinados, visando demonstrar que a preocupação com a democracia é relativizada na própria evolução do Sistema-Mundo. A questão da projeção da democracia para além dos limites internos ao Estado-Nação, se propagando para o âmbito das relações internacionais e questionando a própria primazia do ator estatal, é mais de fundo moral que necessidade real sistêmica. Em seguida, avaliamos a "questão do déficit democrático" no sistema internacional, 
especialmente no que se refere aos parâmetros utilizados para avaliar se um Estado é democrático e as implicações disto para o sistema interestatal.

\section{A DEMOCRACIA NO SISTEMA INTERESTATAL E NOS PROCESSOS DE INTEGRAÇÃO REGIONAL}

A democracia ou segurança democrática é ponto central da atual agenda internacional, expressa nos casos das regras para o alargamento dos processos integracionistas, por exemplo. Isto exige uma conceituação de democracia, a etimologia da palavra é grega, em que demo significa povo e kracia governo, ou seja, governo do povo. Também pode ser entendida como:

(...) uma das técnicas possíveis de produção das normas da ordenação. Mas é uma técnica que tem características peculiares. (...) reconhecida a impossibilidade de esquivar-se ao principio da divisão do trabalho, a democracia moderna é o sistema de produção das normas da ordenação que confia tal tarefa a um corpo (parlamento) eletivo, com a base mais ampla possível (sufrágio universal) e com método eleitoral proporcional (mesmo sem pretensões de representação), e que funciona, via de regra, segundo o principio da maioria simples. (KELSEN, 2000, p.13)

Para além da produção da identidade entre representados e representantes, Norberto Bobbio (2000, p. 202) destaca a questão da legitimidade do Estado:

(...) um estado democrático é aquele Estado que está baseado num pacto de não-agressão entre diferentes grupos políticos e na estipulação, entre estes mesmo grupo, de um conjunto de regras que permitam a solução pacífica dos conflitos que poderão surgir entre eles.

No caso de processos de integração regional, os Estados-Membros são compelidos a assumirem compromissos de segurança democrática e de solução pacífica de controvérsias, visando garantir com o respeito aos contratos um clima favorável aos negócios. Daí que segundo valores não-ocidentais ou antissistêmicos, a democracia ser vista como uma ordenação civilizacional utilizada pelo Ocidente, quase uma palavra da moda, um símbolo, onde o modelo ocidental é democrático e o resto do mundo não. O ocidente é civilizado o resto do mundo não (MAHBUBANI, 2008).

Um Estado democrático implica na existência de eleições livres nas quais se defrontam múltiplos partidos, na existência de meios de comunicação sem controle político do governo, no direito de professar uma fé religiosa sem interferência do governo, enfim, em "liberdades civis" que devem ser praticadas dentro das fronteiras de um Estado (WALLERSTEIN, 2004). Não é possível estabelecer quantas regras são necessárias para que um regime seja considerado democrático, mas se sabe que a ausência desses elementos citados constitui um regime não-democrático.

Não obstante, a Freedom House (ONG internacional de acompanhamento da questão democrática) estabelece uma metodologia para verificar se um país é democrático ou não, e estabelece uma classificação entre os países determinando se é livre, parcialmente livre e não livre (Tabela 01).

Tabela 01 - As Tendências Globais de Liberdade

\begin{tabular}{c|c|c|c}
\hline Ano em análise & 1995 & 2000 & 2005 \\
\hline Livre & 76 & 86 & 89 \\
\hline Parcialmente Livre & 62 & 58 & 58 \\
\hline Não Livre & 53 & 48 & 45 \\
\hline Total dos países & 191 & 192 & 192 \\
\hline
\end{tabular}

Fonte: Disponível no site www.freedomhouse.org 
Para Samuel Huntington (1994), as variáveis possíveis para medir a democracia incluem alto nível de riqueza, distribuição de renda relativamente igualitária, economia de mercado, modernização social, desenvolvimento econômico, democracia patriarcal, burguesia forte, classe média forte, alto nível de alfabetização e instrução, protestantismo, pluralismo social, liberdade de contestação política, estruturas democráticas no interior dos grupos sociais, baixos níveis de violência civil, reduzido grau de extremismo, líderes políticos comprometidos com a democracia, tradição de tolerância, tradição de respeito à lei e aos direitos individuais, homogeneidade comunal (étnica, racial e religiosa), consenso sobre valores na sociedade, entre outros aspectos, e quase sempre numa combinação destas causas. Apenas para constar, Samuel Huntington é autor do paradigma do Choque de Civilizações, considerado pelos realistas como uma estratégia de contenção do Ocidente contra eventuais desafiantes regionais "não-Ocidentais".

Para Zhebit (2005), o melhor meio de testar a democracia é dirigir-se aos cidadãos, querendo saber a sua vontade, conferindo o universalismo dos direitos e liberdades com a sua aceitação pelas sociedades e pelos institutos sociais, religiosos e culturais. Embora a democracia liberal seja um processo mais quantitativo que qualitativo, pois efetivamente houve um aumento do número de pessoas com direito a voto e multiplicação de órgãos representativos, pouco foi feito no sentido de ampliar a qualidade da democracia nos países e entre os países.

Wallerstein (2004) considera que outras questões afligem os Estados liberais democráticos, como corrupção, desigualdades materiais e cidadania ineficiente. E que estas foram agravadas com o desmonte do Estado do Bem-Estar Social ou Walfare
State, que impôs novos padrões para sua população, em saúde, educação e renda vitalícia. Assim, Wallerstein (2004), argumenta que a formação do território nos processos integracionistas está intimamente ligada à estruturação de suas políticas institucionais, e que simultaneamente, são produtos e produtoras da complexa realidade social da economia-mundo.

\subsection{A Questão Democrática nos processos de integração regional: o caso da integração sul-americana}

\section{A América Latina apresenta diversas} tentativas políticas em curso de gerar uma integração regional e uma inserção mundial fundamentada em valores próprios, isto é, numa leitura latino-americana do Sistema-Mundo. Entretanto, suas próprias articulações ainda aparecem fragmentadas temática e geograficamente. No campo social, a proposta da Alternativa Bolivariana para as Américas (Alba) lançada pela Venezuela de Hugo Chávez, se aproximou de Bolívia, Nicarágua e Cuba. Seus idealizadores argumentam que o projeto da Alba é um enfrentamento dos povos latino-americanos e caribenhos contra o imperialismo, frequentemente lembrando a tentativa do Executivo estadunidense tempos atrás de efetivar a Área de Livre-Comércio das Américas (Alca).

No campo comercial, encontra-se o Mercosul, criado através do Tratado de Assunção, assinado em 1991, entre Argentina, Brasil, Paraguai e Uruguai, e visa à constituição de um mercado comum entre os Estados-Partes. Recentemente a Venezuela aderiu ao bloco (faltando ainda seu reconhecimento por parte dos parlamentos nacionais dos atuais membros), representando o único país como elo entre as propostas integracionistas regionais no campo social e comercial. $\mathrm{O}$ 
Mercosul tem como Estados-membros a Argentina, Brasil, Paraguai, Uruguai e Venezuela, como Estados-associados Bolívia, Chile, Peru, Colômbia e Equador e também tem como Estado-observador o México. As instituições e também os aspectos normativos do Mercosul são metas, todavia mais amplas no campo da integração e deveriam ser prioritárias entre os países integrantes do bloco.

Finalmente, concebida como cimento político da integração regional, encontra-se a União das Nações Sul-Americanas (Unasul) que tem como objetivo a integração da região para além do campo econômico, incluindo uma agenda política e social. Seu equivalente no campo da defesa seria o Conselho de Defesa Sul-Americano (CDS), que visa uma maior integração do setor da defesa dos países sul-americanos, com elaboração conjunta de planos de ação, intercâmbio entre os países e identificação de ameaças regionais, sempre buscando uma ação conjunta e melhor integração entre os países da região.

Os governos nacionalistas e de esquerda da região desejam abandonar, ainda que em velocidades e graus distintos, as políticas neoliberais do Consenso de Washington, olhando para as questões sociais e buscando uma maior independência do centro hegemônico (no momento os EUA). Mas os países sul-americanos não parecem buscar uma mudança profunda na estrutura do sistema, e sim uma mudança nos valores do atual sistema, especialmente centrada na crítica à atual política da potência hegemônica e seus objetivos particularistas projetados no sistema mundial. Pode-se verificar isso analisando os discursos das atuais lideranças dos governos nacionalistas, de esquerda e de centro-esquerda sul-americanos envolvidos nos processos de integração e cooperação regional.

Entretanto, para além do discurso, esses governos também têm buscado ações internas como a reativação de empresas estatais ou experienciando formas de economia solidária, mas a prática parece mais promissora quando dos esforços de institucionalizar suas ações numa perspectiva multidimensional (econômica, política, social e militar), esperando promover uma maior integração regional independente dos centros hegemônicos. Neste último caso, democracia e cooperação regional andam lado a lado, rompendo com os padrões de imitação segundo determinações extra-regionais.

Até que ponto essas propostas de organização institucional serão capazes de efetivar a retórica dos discursos das lideranças regionais é questão em aberto. Sempre que os governos dão mais importância aos lideres do que às instituições, é a população quem perde, ocorrendo um simulacro de democracia (KHANNA, 2008).

Não pode ser esquecido que a promoção do liberalismo e da cooperação regional aberta são também as "melhores armas do Ocidente" (KHANNA, 2008, p. 186) ${ }^{1}$. Nessa linha, Seitenfus (1992) diz que o entendimento regional é um fenômeno marcante do sistema internacional, elaborado a partir da vontade de superar rivalidades históricas começando pelo caráter comercial. Mesmo S. Huntington (1997, p.161) reconhece que:

(...) as regiões são a base para a cooperação entre os Estados, unicamente na medida em que a geografia coincida com a cultura. Divorciada da cultura a proximidade não gera por si só aspectos em comum e pode mesmo induzir exatamente o oposto.

Se a integração regional integra a lógica organizativa territorial e de mercados do capitalismo globalizado, talvez não represente a afirmação exatamente dos mesmos valores sistêmicos. Portanto, a questão da democracia não pode ser um

${ }^{1}$ Khanna cita o diplomata brasileiro Celso Amorim, quando este declara que "a integração é um imperativo, pois, num mundo de grandes blocos, seremos mais fortes se nos unirmos." 
dado ou valor exógeno aos processos integracionistas regionais, mas deve emergir de necessidades e consensos internos. São os atores dos blocos regionais que devem decidir se os processos integracionistas devem ser mais abertos (pró-ocidentais) ou fechados.

As relações extra-blocos podem ser comparadas à política exterior de cada país e, esta última, se refere à presença da independência e segurança destes, além da perseguição e proteção de seus interesses econômicos (MIYAMOTO, 2002). Assim, nem sempre a questão da segurança democrática sob a premissa de economias abertas (livre-mercado) resulta na independência e proteção dos interesses nacionais ou coletivos regionais, justamente pelo status quo do sistema internacional ou da ordem liberal ocidental (GILPIN, 2004).

\subsubsection{Mercosul}

O próprio Mercosul inclui uma cláusula democrática através do Protocolo de Ushuaia (1998), no qual seus membros afirmam que a plena vigência das instituições democráticas é condição indispensável para a existência e o desenvolvimento do Mercosul. A condição democrática é, portanto, condição para a adesão e para a permanência no bloco.

O Protocolo de Ushuaia, estabelecido entre os Estados-Partes do MERCOSUL, em seu artigo $1^{\circ}$, afirma que, "a plena vigência das instituições democráticas é condição essencial para o desenvolvimento dos processos de integração entre os Estados-Partes do presente Protocolo". O artigo $2^{\circ}$ do referido protocolo traz que a aplicação do artigo $1^{\circ}$ se dará no caso de ruptura da ordem democrática em algum dos Estados-Partes. No artigo $4^{\circ}$ define-se que no caso de ruptura da ordem democrática em um Estado-Parte do Protocolo, os demais Estados-Partes promoverão consultas pertinentes entre si e com o Estado afetado.

Evidente que é preciso lembrar que o MERCOSUL surge num contexto de preocupação dos Estados da Bacia do Prata com a consolidação da democracia na região e em todo o continente. A Argentina restaurava a democracia em 1983; o Brasil saiu de um longo período de regime militar (1964-1985) ao restabelecer a democracia em 1985; o Paraguai se redemocratiza em 1989, e o Uruguai em 1984. Assim, a assinatura do Tratado de Assunção de 1991 seria marcado pela preocupação dos recém democratizados Estados da região em impedir o retorno dos militares ao poder.

\subsubsection{Organização dos Estados Americanos (OEA)}

A OEA tem como objetivo consolidar a paz e a segurança no Hemisfério e promover e consolidar a democracia representativa na região, dentre outros, e a Carta Democrática Interamericana reflete a vontade política de seus membros no comprometimento com a democracia. $\mathrm{O}$ documento define os elementos considerados essenciais aos regimes democráticos na região:

A assinatura da Carta Democrática representou um passo significativo na história americana. (...) contudo, necessário se faz que a Organização possua ferramentas que permitam a tomada de atitudes mais efetivas, de modo a prevenir e reagir a qualquer atitude que leve à ruptura da ordem institucional. (FEDOZZI, 2005, p. 167).

A Carta Democrática Interamericana, estabelecida entre os Estados-Membros em setembro de 2001, considera que a democracia representativa é indispensável na região e o propósito da OEA é promover 
e consolidar a democracia. Exige o reconhecimento da OEA para a promoção e consolidação da democracia nas Américas. Traz seu texto que:

Recordando que os Chefes de Estado e de Governo das Américas, reunidos na Terceira Cúpula das Américas, realizada de 20 a 22 de abril de 2001 na Cidade de Québec, adotaram uma cláusula democrática que estabelece que qualquer alteração ou ruptura inconstitucional da ordem democrática em um Estado do Hemisfério constitui um obstáculo insuperável à participação do Governo do referido Estado no processo de Cúpulas das Américas (... $)^{2}$.

É preciso lembrar que os EUA, usando do discurso da democracia e legitimandose na OEA, interveio diversas vezes nos países da região em razão de divergências a respeito dos princípios democráticos, chegando a expulsar Cuba da Organização quando esta instalou um regime socialista, e mais recentemente nada fazendo quanto ao golpe de Estado em Honduras (promovido contra um governo de esquerda).

Khanna (2008) diz que na América do Sul é a incerteza política que tem comprometido o progresso. Para o autor, outro país com problema no que diz respeito aos princípios democráticos na região é a Venezuela, pois Hugo Chávez calou as outras vozes. Embora democraticamente eleito, sua democracia funcionaria como um plebecracia: é Chávez quem nomeia todos os governadores e prefeitos e dá auxílio aos oficiais da reserva que zelam para conservar o status conquistado.

Mas Chávez também realiza ações em benefício da população, como empréstimos subsidiados, créditos agrícolas, redes de distribuição de alimentos e programas preventivos de saúde empregando médicos cubanos. Por outro lado, o governo venezuelano conta hoje com mais de três milhões de pessoas na sua folha de paga-

${ }^{2}$ Disponível em www.oas.org/consejo/pr/AG/Documentos/ AGE-1-28-01\%20portugues.doc. Acessado em: 04 fev. 2011. mento, e Chávez domina ainda toda a Assembléia Nacional e o Conselho Eleitoral.

Khanna (2008, p. 423) contra-argumenta que mesmo nos EUA, a democracia "funciona melhor na teoria do que na pratica. Das nomeações para cargos federais às dos embaixadores no exterior, os presidentes entram e saem do cargo como chefes de panelinhas". Com a Lei Patriótica aprovada pelo Congresso estadunidense, seus dirigentes podem ser ainda menos transparentes, e além do mais a lei viola emendas da Carta dos Direitos, como liberdade de expressão e reunião, proteção diante de medidas injustificadas de busca e captura, pronto julgamento publico e proteção contra castigos cruéis e inusitados.

Assim, a democracia nos Estados Unidos está retrocedendo e não se expandindo, de forma que Khanna (2008, p. 427) fala que "muita riqueza e extravagância levam ao pior de todos os governos, a olocracia das elites, praticamente preocupadas apenas em impedir que outros ganhem supremacia".

\subsection{A Questão Democrática nos processos de integração regional: o caso da Europa}

Na União Europeia também não são admitidos países sem a qualificação da democracia em suas instituições, e este é o motivo da Turquia e dos países do Cáucaso enfrentarem tanta dificuldade em aderirem ao bloco. No Cáucaso, os níveis de desenvolvimento e corrupção estão mais próximos do Terceiro que do Primeiro Mundo ${ }^{3}$ (KHANNA, 2008), e na Turquia há o grave problema da

\footnotetext{
3 O termo primeiro, segundo e terceiro mundo se referem à época da Guerra Fria onde o mundo foi organizado dessa forma, com os países que pertenciam ao primeiro mundo sendo os capitalistas, do segundo mundo os socialistas e do terceiro mundo aqueles não aliados com economia pouco desenvolvida e aqui se utiliza o termo para salientar as diferenças principalmente econômicas e políticas desses países que lutam para se integrar ao mundo capitalista.
} 
representação política dos curdos e da força do Islamismo Político.

O alargamento da União Europeia está pautado na exigência de regimes democráticos, com direito de voto e instituições democráticas. A União Europeia está interessada na estabilidade política e social, fundamentalmente, para ter maior segurança nos investimentos europeus e empresas europeias que invistam nesses mercados (KHANNA, 2008).

Em 2000 foi instalada uma organização internacional denominada Comunidades de Democracias em Varsóvia, em que os países que a integram se comprometem com os processos da democratização. Outra organização internacional instalada recentemente na Europa é a chamada Opção Democrática, que busca ajudar os países do leste europeu a se democratizarem (ZHEBIT, 2005). São ONGs poderosas que visam moldar os países daquela região segundo os padrões institucionais da Europa Ocidental.

Nos anos 1990, a maioria dos governos do mundo passou a ser oficialmente considerada democrática. Segundo dados da Freedom House (apud ZHEBIT, 2005), 117 países têm democracias eleitorais, mas apenas 88 têm democracias liberais. As democracias constituem $45 \%$ da população mundial e são responsáveis por $89 \%$ da produção global. Ao mesmo tempo, as democracias liberais respondem por cerca de $85 \%$ das despesas militares globais. Das 10 maiores economias mundiais, oito são governadas por líderes cujo poder se baseia em eleições livres e justas.

A difusão da democracia tem implicações profundas para as relações internacionais. Na ótica kantiana ou internacionalista liberal, as democracias são mais amantes da paz do que outros regimes e raramente lutam umas contra as outras. Essa visão

\footnotetext{
4 Como lembra Khanna (2008), seguramente esse não é o caso da China, que estabelece acordos comerciais em busca de matérias-primas e energia sem se preocupar com o regime político nos países com os quais estabelece acordos.
}

não é inocente, pois se deduz que as guerras existem porque os países autoritários lutam contra democracias e entre si. Ainda, as democracias garantem e promovem direitos humanos, mercados e instituições constitucionais.

(...) a expansão de democracia significa o sucesso da liberdade. A utilidade da democracia consiste em ser um meio de conseguir paz e segurança em nível global. $\mathrm{Na}$ medida em que este fenômeno continue, o avanço da democracia significa a expansão da zona de paz no mundo. Um mundo predominantemente democrático significaria um mundo livre de violência. (ZHEBIT, 2005, p. 46).

Como se percebe, essa é outra série de argumentos nada inocentes, pois o respeito apenas formal às leis garante a adequação do ambiente de negócios, mas não a resolução dos problemas sociais das nações periféricas.

\subsection{A Questão Democrática nos processos de integração regional: o caso dos países asiáticos}

Para muitos, os países economicamente mais desenvolvidos do Leste Asiático são justamente aqueles que respeitam os direitos individuais e a democracia, casos de Coreia do Sul, Taiwan e Japão. A democracia estaria intimamente ligada à ordem liberal mundial, pois o liberalismo necessita de uma classe média suficientemente grande e democratização da economia para que se realize plenamente. Mas Khanna (2008) analisa que as sociedades asiáticas colocam a democracia apenas como um meio para alcançar um fim, com suas sociedades abertas, mas organizações fechadas.

Argumenta Khanna (2008) que em Cingapura e Malásia existem partidos políticos de oposição e são realizadas eleições, mas 
nunca para o cargo máximo, que é feito por seleção. Ainda assim, essa forma de governo de partido único da Malásia e Cingapura é mais transparente que nas Filipinas, onde sua democracia convive sempre com rumores de golpe de estado. Na Tailândia e em Taiwan, a democracia resultou em sistemas eleitorais imperfeitos, com amplos espaços para manobras ilegais e golpes. E na Indonésia há muita corrupção e a democracia não se estabelece de forma adequada.

Khanna (2008) analisa que a China possui mais liberdades que a Índia democrática, pois a vinculação entre comércio e desenvolvimento presente na China encontra-se ausente na Índia. Na China, o índice de alfabetização é mais alto e de pobreza mais baixo que na Índia. E quando há falta de liberdade econômica (renda), a população não tem como desfrutar das outras liberdades, afirma Khanna. Para a China, a democracia é uma ferramenta destinada a combater a corrupção e aumentar a transparência, e não uma forma de competitividade política. Com população tão grande, o recurso das petições e abaixo-assinados continua sendo armas mais eficazes que a democracia. (KHANNA, 2008).

O governo chinês defende-se alegando que não poderá atender às exigências externas de democratização enquanto sua população não possuir uma renda media de padrões internacionais, pois suas prioridades são a organização interna e não externa. Assim, nas suas relações comerciais com outros países, a China não se preocupa com os regimes políticos existentes, apenas nos benefícios econômicos que pode extrair como matérias-primas e outros insumos industriais para sua grande demanda interna.

Para Bobbio (2000), sempre os rivais competirão no sistema internacional para ver quem tem serviços secretos mais eficientes, espiões mais confiáveis. Enfim, os Estados nacionais apenas poderão se tor- nar totalmente democráticos quanto toda a sociedade internacional for democrática: "o principal efeito do ausente processo de democratização da ordem internacional consiste no fato de que o único modo de resolver os conflitos que surgem no sistema internacional ainda é em última instância o do recurso ao uso da violência recíproca". (BOBBIO, 2000, p. 202) ${ }^{5}$.

Para Wallerstein (2004), a democracia não é realizada nem mesmo nos Estados liberais, e sempre estará limitada na prática, embora na teoria seja incessantemente pregada e divulgada como sinônimo de desenvolvimento econômico e social.

\section{CONSIDERAÇÕES FINAIS}

A democracia se estabelece de forma diferente na teoria e na prática interna e externa dos Estados e dos processos integracionistas. Em muitos países ela pode se apresentar como formal, e na essência deixar a desejar, como na Venezuela, Índia, Filipinas, Indonésia, Cingapura, Malásia... Mas acaso os EUA com sua Lei Patriótica e ingerência em assuntos internos das outras nações soberanas seria exemplo de democracia?

A democracia seria a garantidora da liberdade civil, mas na sociedade capitalista ocorre um deslocamento destas liberdades quando não há liberdade econômica. E a liberdade econômica não pode ser compreendida apenas pelo liberalismo do laissez-faire - do livre-mercado e do direito de propriedade privada -, pois se nem toda a população possui recursos financeiros a liberdade será sempre deficitária.

Os países procuram se definir como democráticos e muitas instituições integracionistas regionais pregam a

Ainda assim, o autor é otimista ao constatar que o numero de estados democráticos tem aumentado e o processo para democratização da sociedade já está em andamento. 
democracia como modelo ideal. Na América do Sul, o Mercosul, através do Protocolo de Ushuaia, define que a democracia é necessária para aderir ao bloco, e a Organização dos Estados Americanos (OEA), em sua Carta Democrática, prega que qualquer rompimento com a ordem democrática representará que esse país deixe a Organização. Mas sempre voltamos às mesmas questões: Quem define o que é democracia? Quais sociedades e países podem se atribuir o direito de julgarem quem é ou não democrático no sistema internacional? Quais instituições internacionais têm legitimidade de intervir em Estados considerados nãodemocráticos?

A União Européia exige de novos membros o atendimento a certos padrões democráticos, num entendimento de processo de integração que ultrapassa o campo econômico e abrange o nível político-social (ou seria o campo econômico que se projeta para o político-social?). Isso faz com que a União Europeia se preocupe com os regimes políticos dos países com os quais mantêm acordos, pois como recorda Khanna (2008), o liberalismo necessita de um mercado livre e com certa ordem, em que a instabilidade do sistema é extremamente prejudicial para que os investimentos externos se multipliquem, objetivo das grandes corporações que atuam no mercado internacional.

Como lembra o modelo chinês, liberalismo econômico e democracia política são indissociáveis apenas no modelo ocidental, e ainda assim não como regra histórica como demonstraram as ditaduras desenvolvimentistas latino-americanas. Aos países periféricos que acreditam no modelo ocidental de liberalismo econômico e democracia política o resultado pode ser o da perpetuação das assimetrias entre os países e povos.
A democracia deve ser um meio e não um fim em si mesma; deve ser utilizada de forma o mais correta possível em cada país, pois não ha fórmula universal a ser aplicada a todos, e cada país tem suas especificidades históricas, culturais, sociais... Muitas vezes, o liberalismo econômico e as liberdades civis propostas pelo modelo das sociedades democráticas ocidentais apenas reforçam a hierarquia do sistema internacional, fazendo com que a desigualdade e a falta de liberdade se perpetuem. As instituições internacionais econômicas ou políticas não praticam a igualdade entre os Estados que tanto anunciam retoricamente, pois em um mundo desigual só pode haver democracias desiguais.

\section{REFERÊNCIAS}

BOBBIO, N. O futuro da democracia. Tradução de Marco Aurélio Nogueira, São Paulo: Paz e Terra, 2000.

CARR, E. H. Vinte anos de crise 1919 - 1939: Uma Introdução ao Estudo das Relações Internacionais. Brasília: Editora Universidade de Brasília, 1981.

Carta democrática interamericana. Disponível em: http:/ / www.oas.org / consejo/pr/AG/Documentos/AGE-1-28-01\%20portugues.doc. Acessado em: 04 fev. 2011.

Dados sobre Liberdade mundial. Disponível em http:/ / www.freedomhouse.org. Acessado em: 04 fev. 2011.

Declaração Alba. Disponível em: http:/ /www. alternativabolivariana.org. Acessado em: 10 jun. 2010.

FEDOZZI, M. C. G. Sistema Interamericano. Texto apresentado no Seminário Lideranças Regionais: Segurança Internacional, realizado entre a Escola Superior de Guerra e a Universidade de Brasília. ESG, Rio de Janeiro, 30 jun. 2005.

GANDIN, D. Escola e transformação Social. 5 ed. Petrópolis: Vozes, 1998.

GILPIN, R. O Desafio do Capitalismo Global. Rio de Janeiro: Record, 2004. 
HOBSBAWM, E. J. A Era das Revoluções. Rio de Janeiro: Paz e Terra. 1996.

HUNTINGTON, S. A terceira onda: a democratização no final do século XX. São Paulo: Editora Ática, 1994.

HUNTINGTON, S. O choque de civilizações e a recomposição da ordem mundial. Rio de Janeiro: Objetiva, 1997.

KHANNA, P. O Segundo Mundo: Impérios e influências na nova ordem mundial. Tradução de Clovis Marques. Rio de Janeiro: Intrínseca, 2008.

KELSEN, H. A democracia. 2 ed. São Paulo: Martins Fontes, 2000.

MAHBUBANI, K. Argumentos en contra de occidente. Disponível em: http://www.fal. itam.mx/descargas/fal_julio_2008/14_Kishore_ Mahbbudani.pdf. Acessado em: 11 nov. 2010.

MIYAMOTO, S. O Mercosul e a Segurança Regional: uma agenda comum. São Paulo em Perspectiva. v. 16, n. 1, São Paulo, 2002.

NYE JR., J. S. O paradoxo do poder americano. Gradiva: Lisboa, 2005.

Protocolo de Ushuaia. Disponível em: http:// www.mercosul.gov.b. Acessado em: 22 jan. 2011.

SANTOS, M. A Natureza do Espaço: Técnica e Tempo, Razão e Emoção. 2 ed.

São Paulo: Hucitec, 1997.

SEITENFUS, R. Considerações sobre o Mercosul: Dossie América Latina. Estudos Avançados, v. 6, n. 16, São Paulo, 1992.

Tratado de Assunção. Disponível em: http:// www.mercosul.gov.br. Acessado em: 22 jan. 2011.

Unasul e Conselho Sul americano de Defesa. Disponível em: http://www1.folha.uol.com.br. Acessado em: 30 jul. 2010.

WALLERSTEIN, I. O Declínio do poder americano: os Estados Unidos em um Mundo caótico. Tradução Elsa T.S. Veira.; revisão de Cezar Benjamim. Rio de Janeiro: Cotraponto, 2004.

ZHEBIT, A. A nova onde democratizante na CEI (2003-2005). Texto apresentado no Seminário Lideranças Regionais: Segurança Internacional, realizado entre a Escola Superior de Guerra e a Universidade de Brasília, ESG, Rio de Janeiro, 30 de junho de 2005.

Recebido em: 23/02/11 Aceito em: 13/05/11 